\title{
La vivienda, un tema siempre contemporáneo
}

\section{Housing, an ever contemporary topic}

\author{
Maya, Ester y Eftychia Bournazou (comps.) (2012), \\ LA VIVIENDA EN MÉXICO. TEMAS CONTEMPORÁNEOS. \\ Facultad de Arquitectura y Dirección General de Personal \\ ACAdÉmico-unam, MÉxico, 143 PP., ISBN: 978-607-02-3 I79-7.
}

El libro que reseñamos reúne el trabajo de ocho académicos, entre ellos investigadores y estudiantes de posgrado de diversas instituciones como la Universidad Nacional Autónoma de México, Universidad Autónoma Metropolitana unidad Xochimilco, Universidad Autónoma de Tamaulipas y Universidad Autónoma de Ciudad Juárez. Dicho texto fue coordinado por dos profesoras del Programa de maestría y doctorado en urbanismo de la UNAM.

Para el análisis y comentarios al respecto del contenido de este texto es casi obligatorio preguntarse, de inicio, ¿Cuáles son los temas contemporáneos de la vivienda en México, y cuán presentes están en esta obra? Cabe señalar que la vivienda en México es indudablemente un tema contemporáneo no sólo para la población que la demanda, sino también para quienes participan directa e indirectamente en su proceso de producción (y aquí se incluyen los sectores público, privado y social), así como para quienes la estudian en relación con el crecimiento de las ciudades.

La revisión de los distintos capítulos permite identificar antiguos y nuevos temas, ambos contemporáneos: los primeros, porque en efecto, persisten hasta la actualidad con distintas miradas para su comprensión, e incluso solución; los segundos, porque se han conformado recientemente como fenómenos que conviene observar y que forman parte de las cuestiones que hoy preocupan a los estudiosos de los temas urbanos. Esta reseña, por tanto, comenta el contenido de la obra en dos partes: la primera hace referencia a los capítulos que abordan los antiguos temas, mientras que la segunda hace lo propio con los nuevos.

En este sentido, son cuatro los capítulos que, a juicio de quien escribe, abordan los asuntos que persisten como preocupación de la problemática habitacional en México: el capítulo inicial de Esther Maya ratifica la relación entre pobreza, marginalidad, desigualdad y la vivienda en el ámbito urbano. En una revisión conceptual de la pobreza urbana en México -de sus metodologías de medición y de la clasificación-, que en su momento 
fuera oficial, haciendo referencia específicamente a la pobreza alimentaria, de capacidades y patrimonial, ${ }^{1}$ la autora advierte que evidentemente la pobreza de patrimonio es mayoritariamente urbana (p.16).

$\mathrm{Al}$ referirse a la pobreza de patrimonio, Maya advierte que "la población que no puede obtener los mínimos aceptables de vivienda, vestido, calzado y transporte para cada uno de los miembros del hogar", supone que, "sí cubre necesidades de alimentación, educación y salud" (p. 16).

En torno a esta definición retomo los siguientes puntos: obtener el mínimo aceptable de vivienda con el fin de cuestionar ¿a quién representaría este tipo de pobreza, acaso a los sectores de la población que no pueden pagar una cuota de vivienda propia?, o bien, ¿a aquellos que no tienen capacidad de ahorro para un enganche, o que ni siquiera consiguen pagar una renta?; en otras palabras, la pobreza de patrimonio, ¿comprende sólo a aquellos sectores sin posibilidad de adquirir o poseer la propiedad de la vivienda, o habría otras implicaciones para la obtención del mínimo aceptable?

En efecto, esto no fue del todo claro desde los conceptos institucionales, naturalmente, su aclaración podría haber dado lugar a especificidades en el universo, no sólo de la pobreza urbana, sino sobre todo del déficit habitacional o rezago, que en su estructura se compone tanto de un aspecto cuantitativo (en lo que se refiere a la demanda de una nueva vivienda) como cualitativo (que concierne a la población que, aun habiendo accedido a una morada, ésta no cumple con condiciones de habitabilidad aceptables -en materiales, dimensiones, localización, seguridad jurídica, etcétera).

En relación con lo anterior, discutir el término de pobreza patrimonial, particularmente refiriéndonos al alojamiento, trata de una situación que interpela la cuestión del acceso a un bien tan complejo como la vivienda, tal como complejo y multidimensional debiera ser entendido el concepto de acceso (Fernández, 2004).

Para México, la preocupación por el acceso a la vivienda en la política habitacional de la década reciente (2000-2011) ha resultado ciertamente un tema clave; sin embargo, éste ha sido interpretado sólo como una oportunidad desde lo financiero, y de allí surgieron numerosas propuestas e instrumentos como la modificación a las funciones sustantivas de los Onavis, la creación de las Sofoles, y la reincorporación de la banca privada en los créditos hipotecarios.

${ }^{1}$ Esta clasificación tipológica, propuesta por el grupo de expertos del Comité Técnico de Medición de la Pobreza convocado por la Sedesol y cuyo criterio fue el ingreso por persona, tuvo vigencia tanto en la medición de la pobreza como en el diseńo de las políticas sociales aproximadamente desde inicios de 2000 hasta 2008, cuando comienza a utilizarse la metodología de medición multidimensional de la pobreza, ya instaurada por ley, y cuya medición está a cargo del Consejo Nacional de Evaluación de la política de Desarrollo Social Coneval (CTMP, 2002; Dof, 2010; Coneval, 2013). 
En este sentido, y según el enfoque de la política, el acceso estaría garantizado en lo que respecta a hacerse del bien, de la vivienda, lo que a su vez permite garantizar el financiamiento para la producción habitacional; no obstante, otras dimensiones del acceso, como el político, que se refiere a la participación del destinatario en la elección de la solución habitacional, o el económico-espacial, que trasciende la vivienda y alude más bien al acceso a la ciudad y a la economía urbana, no se han resuelto. Se trata además de un acceso condicionado, también, según el universo de atención, basta ver en evidencias que presenta este libro y otros textos recientes (Coulomb, 2010; Infonavit, 2012), que la oferta se ha dirigido principalmente a quienes pueden ser sujetos de crédito.

El planteamiento que Eftychia Bournazou expone en su capítulo retoma también un antiguo tema del que ya urge una confirmación conceptual: abordar a la vivienda como unidad espacial independiente ya no es posible. La discusión debe llevarnos al acuerdo de que hablar de vivienda para los estudios urbanos es hablar de entorno, entendido éste, como bien señala la autora, como "provisor de bienes públicos y asociado a la composición social de los espacios habitacionales" (p. 30). Aunado a ello, Bournazou despliega un interesante tránsito teórico de la marginalidad a la segregación espacial y específicamente habitacional, vinculando estos fenómenos con la importancia que reviste el acceso a los bienes públicos desde las zonas habitacionales.

En delicado contraste con la realidad, la autora presenta algunas mediciones que ilustran el impacto de una política que se ha considerado viviendista, en el sentido más estricto, y subraya:

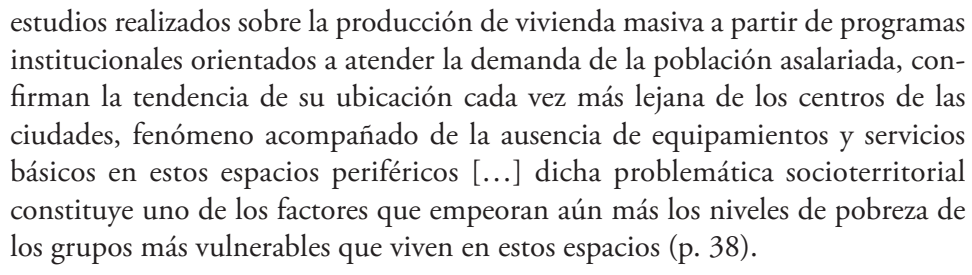

Con lo señalado, el estudio de la segregación tiene utilidad más allá de un preciso retrato de desigualdades territoriales, también tiene la posibilidad de verificar qué impactos socioespaciales puede generar la implementación de una política habitacional.

Por su parte, el capítulo de Vicente Guzmán aborda varios asuntos, dos de ellos en diálogo con los capítulos precedentes: i) insiste en la ruptura necesaria de la delimitación de vivienda como espacio de cuatro paredes y un techo, ii) hace referencia al tema del acceso a la vivienda limitado al acceso financiero desde la gestión de la política, iii) introduce 
el argumento de la sustentabilidad, que si bien no es desconocido, adquiere en el tema habitacional nuevos matices, como el de la sustentabilidad social.

Guzmán retoma además una cuestión, si no olvidada, al menos relegada en la operación de la política reciente, probablemente con cierta intención, que se refiere a la autoproducción habitacional, aproximándose a las etapas y aspectos particulares de este proceso que, aún con los volúmenes de inventario producido desde la formalidad, continúa siendo un modo de acceso común adoptado y preferido por los pobres $-\mathrm{y}$ no tan pobres- en las ciudades de México.

De los temas que persisten en el tiempo, en último lugar, el capítulo de Jorge Cervantes, Esther Maya y José Martínez retoma y concluye algunos trabajos anteriores de los autores que retratan el fenómeno de la vivienda industrializada en la Zona Metropolitana de la Ciudad de México, haciendo hincapié en el propio proceso de industrialización de este producto, donde los volúmenes de la producción e inversión dan cuenta del desenfoque de las acciones desde la política pública.

Los datos sobre créditos y subsidios otorgados por Onavis y entidades financieras, y su correlato en cuanto a inversiones en millones de pesos (p.118), dejan claro cuál ha sido el tipo de acciones habitacionales apoyadas y favorecidas por excelencia: viviendas unifamiliares nuevas, terminadas, en conjunto habitacional (para lo que se invirtiera del orden de 269 mil millones de pesos en 2008), frente a otras acciones de mejoramiento, apoyo a la autoconstrucción o lotes con servicios, que no alcanzan los 2, 000 millones de pesos.

Lo anterior resulta preocupante cuando los datos de rezago que ofrece el Banco Interamericano de Desarrollo en un informe reciente (2011) indican que el déficit habitacional en México está compuesto por $2 \%$ de hogares que carecen de vivienda, déficit cuantitativo, y $26 \%$ de hogares que habitan una vivienda inadecuada por diferentes causas, déficit cualitativo, del cual $9 \%$ remite a la calidad de los materiales con que está construida; $5 \%$ a situaciones de hacinamiento; $8 \%$ a carencia o insuficiencia de infraestructura para la dotación de servicios, y $15 \%$ a la irregularidad dominial, esto es, a la falta de una tenencia segura del suelo y la vivienda (BID, 2011).

Aun así, y habiendo invertido cuantiosos recursos en el tipo de acciones habitacionales arriba señaladas, resultan igualmente alarmantes los datos proporcionados por los autores sobre las inseguridades percibidas en viviendas de conjunto habitacional, detectadas en las encuestas del Laboratorio de Monitoreo de la Habitabilidad de la Vivienda Urbana de la UNAM; así la inseguridad constructiva, estructural y de materiales, sumada a la sanitaria, de servicios, de privacidad, y de comunicación, pre- 
sentan en promedio una frecuencia de $50 \%$ de los casos. Este estudio manifiesta diferentes grados de malestar de los residentes de conjuntos, quienes, $60 \%$ sostienen que si hubiera posibilidad de regresar la mercancía, lo harían (p. 121).

Lo anterior sin duda se refiere a la insustentabilidad que representa -como sostienen los autores- no el tipo de producción industrializada en sí, que lamentablemente se va estigmatizando como práctica de producción negativa, sino a la ausencia de normatividad regulatoria y de sanciones claras y efectivas para cualquier sistema de producción (p. 124).

Otros temas aparecen ciertamente novedosos en los tres capítulos que completan el libro, frente a la realidad de los resultados de las políticas habitacionales y el crecimiento de las ciudades, a saber: en su capítulo, Dulce María Barrios plantea el concepto de sustentabilidad que abordara previamente Guzmán, e incorpora la definición que ubica a "los seres humanos como el centro de las preocupaciones relacionadas con el desarrollo sostenible" (p. 86), confirmando, como también lo hace previamente Bournazou, que el modelo de zonificaciones en el que se ha incorporado a las áreas residenciales proviene de un paradigma insustentable y rebasado que surgió en la Carta de Atenas hace ya unas cuantas décadas.

Específicamente, la sustentabilidad residencial, que preocupa a la autora, forma parte de la sustentabilidad social ligada al bienestar de las personas, y de la sustentabilidad en general. Barrios afirma que: "en el mediano plazo, la consideración de estos aspectos (que según ella refieren a la habitabilidad, como parámetro de calidad en la vivienda, y que incluye componentes psicológicos, espirituales, estéticos, entre otros) hará más barata y eficiente la inversión en vivienda, mejorará la salud social, y mitigará el daño al medioambiente” (p. 93).

Otro tema poco abordado y ciertamente novedoso es el de la vivienda de segunda residencia, que presentan Jorge Cervantes y Rosalía Gómez.

Hay dos elementos en este texto que conviene rescatar: el primero, se refiere a la importancia del fenómeno en el país, ya que los autores señalan que este mercado ha crecido y se ha consolidado fuertemente ante el problema de la recesión en Estados Unidos, producida desde 2008, por lo que sin duda se convierte en un asunto al que es necesario darle seguimiento (pp. 99 y 100).

En segundo lugar, al convertirse México en el más importante mercado potencial de segunda vivienda para ciertos segmentos de población estadounidense, caben dos preguntas abiertas a posteriores reflexiones: la primera es más bien un reto, ¿cómo regular desde los marcos normativos este fenómeno turístico-inmobiliario-residencial?, y la segunda, ¿cómo actuar desde la política, aprovechando dicho fenómeno para apoyar la 
resolución de los rezagos en el país?, en otras palabras, ¿Qué políticas o instrumentos compensatorios pudieran surgir de esto?

El capítulo de Elvira Maycotte nos hace retornar a pensar y discutir si la calidad ha resultado, para efectos de esta política, más que un elemento esencial en la planeación del uso habitacional, una preocupación apremiante después de lo realizado.

La autora expone con detalle algunos casos de conjuntos habitacionales en Ciudad Juárez, mostrando que buena parte de las decisiones en su producción no contemplaron criterios de sustentabilidad, y por lo tanto hoy estos conjuntos experimentan graves problemas derivados de la mala y riesgosa localización, lo que indudablemente incide en las condiciones y calidad de vida de sus residentes. Se han evidenciado incluso situaciones de abandono y vandalización de las viviendas.

En suma, el libro enriquece los debates actuales no sólo de la vivienda, sino de los espacios o ambientes habitacionales en México, tratando tanto los temas que perduran en el tiempo, como las nuevas preocupaciones; parece ser que la vivienda adecuada (onu-Hábitat, 1996), digna y decorosa (Ley de Vivienda, 2006) constituye aún una problemática fundamental. Y en ello, la sustentabilidad y la calidad se han convertido en dos categorías contemporáneas imprescindibles que atraviesan los siete capítulos, generando un diálogo complementario a los señalamientos de cada autor.

Es innegable que en el origen de los debates se encuentran las contradicciones entre el enfoque de la política habitacional (como un fenómeno intencionado, en el discurso y en la práctica) y los resultados socio urbanos obtenidos. Las ideas que se presentan en esta obra resultan estimulantes para continuar indagando y obtener mejores respuestas.

\section{Bibliografía}

BID (Banco Interamericano de Desarrollo) (2011), "Un espacio para el desarrollo de los mercados de vivienda”, Ideas para el Desarrollo en las Américas, http://www.iadb.org/en/research-and-data/publicationdetails,3169.html?displaytype $=\&$ pub_id=IDBNW-104, 31 de marzo 2013.

CTMP (Comité Técnico para la Medición de la Pobreza) (2002), Medición de la pobreza. Variantes metodológicas y estimación preliminar, Secretaría de Desarrollo Social, México.

Coneval (Consejo Nacional de Evaluación de la Política de Desarrollo Social) (2013), "Medición de la pobreza”, http://www.coneval.gob. 
mx/Medicion/Paginas/Medici\%C3\%B3n/Que-es-la-medicionmultidimensional-de-la-pobreza.aspx, 28 de abril de 2013.

Coulomb Bosc, R. (2010), "Evolución reciente y situación actual del derecho a la vivienda”, en G. Garza y M. Schteingart (coords.), II - Desarrollo urbano y regional, El Colegio de México, México.

Fernández Wagner, R. (2004), “La construcción y deconstrucción histórica de lo social en el acceso a los bienes y servicios del hábitat", en INvi, 50 (19), Santiago de Chile, pp. 13-22.

Dof (Diario Oficial de la Federación), "Gobierno de la república, lineamientos y criterios generales para la definición, identificación y medición de la pobreza”, 16 de junio de 2010.

Infonavit (Instituto del Fondo Nacional para la Vivienda de los Trabajadores) (2012), Agenda de vivienda para los próximos 10 años. Vida, trabajo y vivienda para todos, Infonavit, ciudad de México.

Ley de Vivienda (2006), "Ley de Vivienda”, Diario Oficial de la Federación, Cámara de Diputados del H. Congreso de la Unión, 16 de junio de 2011, ciudad de México, pp. 30.

ONU-Hábitat (1996), "Declaración de Estambul sobre los asentamientos humanos", Hábitat II, Estambul.

Recibida: 30 de abril de 2013. Aceptada: 13 de junio de 2013.

Carolina Pedrotti cpedrotti@cmq.edu.mx El Colegio Mexiquense, A. C.

Carolina Inés Pedrotti. Actualmente es candidata a doctora en urbanismo por la Universidad Nacional Autónoma de México, se desempeña como profesora-investigadora en El Colegio Mexiquense. Es arquitecta por la Universidad Nacional de Córdoba, Argentina, maestra en estudios urbanos y regionales por la Universidad Autónoma del Estado de México, con estudios de posgrado en desarrollo, mejoramiento y gestión habitacional en Bolivia y Costa Rica (Universidad Mayor de San Simón, Bolivia, Fundación Promotora de Vivienda, Fuprovi, Costa Rica y Universidad 
de Lund, Suecia). Asimismo, imparte la asignatura Suelo Urbano y Vivienda en la licenciatura en Administración y Promoción de la Obra Urbana en la Universidad Autónoma del Estado de México. Su línea de investigación es el hábitat urbano: fenómenos socioespaciales vinculados a la vivienda y el suelo urbano destinado al uso habitacional. Entre sus publicaciones destacan: "La seguridad de la tenencia del suelo y la vivienda. Dimensiones del fenómeno desde la perspectiva de la pobreza urbana", en Perló-Cohen, Manuel y Martim O. Smolka (coords.) Antología del Programa para la Formación de Expertos en Suelo Urbano-Fexsu III, [CDROOM], UNAM-Lincoln Institute of Land Policy, México, p. 1-44 (2006); "Urbanización y política habitacional dominante en el Estado de México... ¿y el derecho a la ciudad?”, en Paula Peyloubet y Laura de Salvo (comps.), Ciencia y tecnología para el hábitat popular. Articulación de politicas intersectoriales: científico tecnológicas y de inclusión social, Ceve-Conicet-Nobuko, Buenos Aires, pp. 217-232 (2009); en coautoría, "Expansión metropolitana y producción habitacional en la Zona Metropolitana de Toluca”, en Susana Medina Ciriaco (coord.), Contribuciones al estudio de las ciudades, el Estado de México y el suelo urbano, El Colegio Mexiquense, A.C., Zinacantepec, pp. 253-305 (2013). 